\title{
ARQUIVOS
}

\author{
RELAÇÃO DE 134 CÓDICES VALIOSOS PARA \\ UMA EVENTUAI HISTORIA LOCAL DE \\ SANTANA DO PARNAÍBA (1660-1932).
}

Correspondendo ao apêlo do Diretor da Revista de História (1), no sentido do arrolamento de fontes primárias regionais, julgamos oportuno divulgar uma relação de 134 Códices sóbre Santana do Parnaj́ba, no período de 1660-1932, existentes na secção histórica do Departamento do Arquivo do Estado de São Paulo. Trata-se de documentação provàvelmente inédita, recolhida àquela secção especializada em 8 de outubro de 1940 .

Essa documentação é conhecida de funcionários do Arquivo e talvez de um grupo reduzido de historiadores (2). Foi um acaso feliz que nos facultou a tomada de conhecimento de tôda essa impressionante contribuição à história de uma das regiões mais antigas de nossa terra. Especificamente estamos empenhados em solucionar para o $4 .^{\circ}$ distrito da Diretoria do Patrimônio Histórico e Artístico Nacional, o problema dos primitivos moradores de uma casa térrea seiscentista, situada no Largo da Matriz n. ${ }^{\circ}$ 9, na esquina da rua Alvaro Luís do Vale, ne cidade e município de Santana do Parnaíba, neste Estado. Imóvel que mediante edital de notificação de tombamento, publicado na forma do costume na imprensa oficial e oficiosa do país, dentre os quais lembramos O Estado de São Paulo (3), foi inscrito nos Livros do Tombo da DPHAN, sendo que os trabalhos de restauração, iniciados em janeiro de 1959 pelo $4^{\circ}$ distrito, já se encontram em fase de conclusão. Consta que se planeja transformar êsse valioso imóvel seiscentista em um museu regional, centro de estudos sôbre o passado colonial,

\footnotetext{
1). - E. Simões de Paula, in nota de rodapé, pág: 209 da Revista de História n. ${ }^{\circ}$ 39 (julho-setembro de 1959).

(2). - Dentre êles o Monsenlhor Paulo Florêncio da Silveira Camargo, que estando como vigário de Santana do Parnaíba (1924-1926) compulsou alguns códices para colher dados para um dos capítulos do livro: Poliantéia, publicado sob os auspícios da Câmara Municipal de Santana do Parnaíba, em comemorção ao tri-centenário da sua elevação à Vila (14 de novembro de 1925)

(3). - “O Estado de São Paulo", São Paulo, 2 de outubro de 1958.
} 
de inegável atração turística, como vem sendo a Casa do Bandeirante, nesta Capital.

Como se sabe, dentro da linha da DPHAN, além da preoclipação de restauração em bases científicas, há o objetivo de identificação histórica do bem imóvel ou móvel tombado. Focalizando a casa urbana seiscentista de Parnaíba, o Dr. Luís Saia, chefe do $4 .^{\circ}$ distrito da DPHAN, com o pêso de sua grande e indiscutível autoridade, teve oportunidade de esclarecer:

“...estaríamos em face do único exemplar de residência urbana do segundo século na região de São Paulo".

E mais adiante, sob o prisma histórico:

"Mau grado pesquisas já realizadas em documentos que pudessem revelar os primitivos proprietários do local, nada fọi possível conseguir no sentido de estabelecer precisamente a data da construção. Só uma investigação mais minuciosa poderia fornecer os elementos para qualificar o edifício como seiscentista" (4).

Paralelamente ao início dos trabalhos de restauração, então compromissada com o DPHAN, coube-nos iniciar um plano de pesquisas, visando a identificação histórica do citado imóvel. $\mathrm{E}$ depois de seis meses de árduas pesquisas, tivemos a sorte de encontrar um ponto de partida que, eventualmente, nos poderá conduzir à identidade dos primitivos moradores e mesmo à data de construção. Encontrâmo-lo não nos Códices abaixo relacionados, que na continuidade da pesquisa poderiam se tornar valiosíssimos, muito menos nos Maços Coloniais e $\mathrm{Ma}$ pas de População de Santana do Parnaíba, existentes também na secção histórica do Departamento do Arquivo do Estado; muito menos ainda nos quatro Livros do Tombo de Santana do Parnaíba que estão no arquivo da Cúria Diocesana; mas sim no Fórum Civil da Capital - 3. ${ }^{\circ}$ Ofício da Família e Sucessão - secção de Arquivo de Testamentos da Comarca de São Paulo; num Testamento de 1860, catalogado sob o número 685 .

Encerrando estas notas introdutórias, seja-nos permitido considerar que Santana do Parnaíba, situada às margens do Tietê, distante 31 quilômetros desta Capital, em linha reta; com uma área de 410 quilômetros quadrados para uma populução de 10.411 habitantes (5), representa um patrimônio his-

(4). - Luís Saia, Notas sôbre a arquitetura rural paulista no segundo século, in Revista SPHAN. Rio de Janeiro, 1944, n o 8, págs. 241-261-271.

(5). - IBGE, Enciclopédia dos municípios brasileiros. Rio de Janeiro, 1958, vol. Xxx. (Santana do Parnaíba, págs. 106-108). 
tórico dos mais expressivos. Sua origem remonta ao quinhentismo, pois em 1580 já possuia uma Capela (Nossa Senhora de Santana) provisionada, que lhe facultava alinhar-se na linha de frente das três primeiras povoações civilizadas erectas no planalto de Piratininga: Santo André da Borda do Campo, São Paulo de Piratininga e Santana de Parnaíba. Esta última pasou à Vila em 14 de novembro de 1625 e, sòmente com a denominação de Parnaíba, foi levada à categoria de Cidade a 19 de novembro de 1906. Em conseqüência de reiteradas solicitações, voltou a denominar-se Cidade e Município de Santana de Parnaíba, em função do decreto-lei n. ${ }^{\circ} 14.334$ de 30 de novembro de 1944 .

Assim, a cidade de Santana de Parnaíba, além de outros bens móveis e imóveis já identificados e reverenciados pelos moradores e visitantes, conta com o privilégio de conservar a segunda residêncica urbana conhecida, em antigüidade, de todo o país (a mais antiga conhecida é a de Olinda).

Uma outra prioridade, em São Paulo, caber-lhe-á reivindicar - graças aos Códices abaixo relacionados em ordem cronológica, como também à documentação conhecida e identificada em arquivos públicos e particulares, até a presente data - Santana do Parnaíba passa a ser, ao lado desta nossa Capital e da cidade e município de Itú, uma das cidades mais bem apetrechadas em fontes primárias indispensáveis a uma autêntica História Local, como também das regiões circunvizinhas, a ser eventualmente escrita.

RELAÇÃO DOS CÓDICES EM ORDEM CRONOLÓGICA.

\section{Século XVII.}

Vol. 1. - Livro de Escrituras e Procurações do Tabelião de Parnaíba. Período de 1660-1662. Códice restaurado. Fôlhas sem numeração. A capa traz as seguintes indicações: 1660/ - Anto. Rioz de Mattos... e findou no anno de 1662 .

Vol. 2. - Atas da Câmara da vila de Santana de Parnaíba. Período de 1679-1692. Códice restaurado, com nova numeração. Fôlhas 3 a 66 , duplicada a fôlha 19. Seguem, no mesmo volume fôlhas com numeração nova de 2 a 18. Cumpre alertar que, encadernado com o Códice, pode ser encontrado um interessante exemplar do jornal Paulista Oficial, impresso em São Paulo com a data de 29 de setembro de 1835 , com 4 páginas; ainda 0 $88 .^{\circ}$ número do mesmo periódico. 
Século XVIII.

Vol. 3. - Livro de Vereanças da Câmara da vila de Parnaíba. Período de 1726-1740. Códice restaurado, conservado em bom estado, encadernação primitiva em pano. Instrumenta 242 fôlhas numeradas com a rubrica Rocha.

vol. 4. - Livro de Vereanças da Câmara da vila de Panaíba. Periodo de 1757-1756. Códice em bom estado, encadernado em couro marron bem escuro, com uma inscrição na capa que nāo nos foi possível decifrar. Instrumenta 152 fôlhas marcadas com a rubrica Mello; duas fôlhas não trazem numeração.

Vol. 5. - Livro de Vereanças da Câmara da vila de Parnaíba. Período de 1757-1764. Códice em bom estado, com encadernação em couro marron escuro. Fôlhas numeradas e rubricadas por Filgr.as, mas apresentando a seguinte particularidade: de 1 a 119 , depois de 121 a 137 , duplicada a fôlha 137 que segue até 150, duplicada esta vai até 240 .

Vol. 6. -- Livro de Eleições. Período de 1787-1828. Códice em bom estado, instrumentado por 100 fôlhas numeradas com a rubrica Velozo e Gama.

Vol. 7. - Livro dos defuntos da Igreja Paroquial de Nossa Senhora da Penha de Fr.ca de Sariguama de 1721 annos. Período de 1720-1721. Códice muito interessante, mas necessitando de restauração. Instrumenta 226 páginas rubricadas pelo Pe. Joseph da Fon.ca. Cumpre inforformar que junto à página de rosto do citado códice está apenso um codicilo de cêrca de 21 x 15 ctms. com o seguinte título: "Livro dos assentos dos defuntos que morreram neste bairro de Sariguama de 1720 annos". Trata-se de um codicílio de 37 fôlhas também necessitando de restauração.

Vool. 8. - Livro de Receita e Despêsa da Câmara da Vila de Parnaíba. Período de 1722-1745. Códice em estado regular, encadernado em couro marron. Com 177 fôlhas com a rubrica Manso.

Vol. 9. - Livro de Receita e Despêsa da Câmara da Vila de Parnaiba. Periodo de 1722-1755. Códice em estado regular, encadernado em couro marron; com 142 fôlhas assinaladas com a rubrica Manso.

Vel. 10. - Livro para os Capítulos de Correição e Têrmos de Aforamento. Periodo de 1722-1828. Códice em bom estado, encadernado em marron. Integra-o 150 fôlhas numeradas com a rubrica Manso.

Vol. 11. - Livro de Registros da Câmara da Vila de Parnaíba. Período de 1723-1743. Códice em estado regular, encadernado em couro marron. Integra-o 150 fôlhas numeradas com a rubrica "Ferraz". 
Vol. 12. - Livro de vereanças da Câmara da Vila de Parnaíba. Periodo de 1726-1740. Códice restaurado, conservado em bom estado; encadernação primitiva em pano. Integra-o 242 fôlhas numeradas com a rubrica Rocha.

Vol. 13. - Livro de Notas do Tabelião de São Paulo. Período de 1730-1731. Lamentàvelmente êsse Códice está em péssimo estado, necessitando de breve restauração, a fim de evitar a total destruição. Um fragmento da capa, de pano, faculta identificar a seguinte indicação: "1730-1731. Matos-Guzmäo".

O têrmo de encerramento diz tratar-se de um livro de Notas, com "Sento e vinte eseis meyazs folhas numeradas e rubricadas pello Juiz Ordinario Manoel do Prado de Siq.ra aos doze de Julho de 1730".

Vol. 14. - Livro de Correições dos Vereadores e dos Almotacéis. Período de 1741-1755. Códice em bom estado; encadernado em pano. Integra-o 198 fôdhas numeradas com a rubrica Campello.

Vol. 16. - Livro de Assento dos Presos. Período de 1741-1831. Códice em péssimo estado, necessitando de urgente restauração, a fim de evitar a sua total destruição. Integra-o 99 fôlhas numeradas com a rubrica M. Campello.

Vol. 17. - Livro de Despesas da Câmara. Período de 1742-1789. Códice em estado regular. Integra-o 254 fôlhas numeradas com a rubrica M. Campello.

Vol. 18. - Livro de Provimentos dos Carregadores da Comarca nos Autos das Correições. Periodo de 1742-1828. Códice em bom estado. Integra-o 189 fôlhas numeradas com a rubrica Caméllo.

Vol. 19. - Livro de Notas do Tabelião de Santana de Parnaíba. Periodo de 1743-1745. Códice em péssimo estado, clamando por imediata restauração. Integra-o 132 fôlhas com a rubrica Rocha.

Vol. 20. - Livro de Registros da Câmara de eleições dos Juízes e mais oficiais. Periodo de 1743-1788. Códice em bom estado. Integra-o 128 "Meyas folhas", rubricadas por João davila do Canto e, posteriormente, por José Luiz de Brito Mello.

Vol. 21. - Livro de Notas do Tabelião da Vila de Parnaíba. Periodo de 1744. Trata-se de um Códice em bom estado, se bem que precisando de ser restaurado e encadernado. Integra-o 475 fôlhas com a rubrica Filgras.

Vol. 22. - Livro de Vereadores da Câmara da Vila de Parnaíba. Periodo de 1751-1756. Códice em bom estado, encadernado em couro marron escuro, trazendo na capa inscrições que nos pareceram ilegiveis. Integra-o 2 fôlhas sem número; e as 152 fôlhas restantes com a rubrica Mello.

Vol. 23. - Livro de Receita e Despêsa da Câmara da Vila de Parnaíba. Periodo de 1755-1816. Códice em bom estado; 
encadernado em pano. Integra-o 194 fôlhas com a rubrica Filg.as.

Vol. 24. - Livro de Registros de Licenças da Câmara de Parnaíba. Período de 1756-1799. Trata-se de um Códice em bom estado, encadernado em couro marron. Instrumenta-o 153 fôlhas com a rubrica Mello.

Vol. 25. - Livro de Vereanças da Câmara da Vila de Parnaíba. Período de 1757-1764. Trata-se de um Códice em bom estado, encadernado em couro marron, apresentando a seguinte peculiariedade: numeração das fôlhas 1 a 119 ; de 121 a 137; duplicada de 137 até 150; duplicada a 150a. que segue até a 240 . Tôdas elas com a rubrica Filgr.as.

Vol. 26. - Livro de Rol das Culpas do Juiz da Vila de Parnaíba.? Período de 1763-1769. Trata-se de um Códice que está clamando por uma restauração. Instrumenta-o fôlhas não numeradas, apenas com a rubrica Viegas. Como curiosidade vale a pena assinalar que se trata de um Códice em forma de índice, se bem que não encadernado.

Vol. 27. - Livro de Sumários das Querelas do Juízo da Vila de Parnaíba. Período de 1763-1810. Trata-se de um Códi. ce em bom estado; instrumentado por 50 fôlhas com a rubrica Rocha.

Vol. 28. - Lista das pessoas "a q.m os off.as da Cam.a desta V.a encarregaraô....... deslguldão, comforme aordem do Illmo. e Exmo. Sr. Governador eCapp.am Gen.al desta Cap.t D. Luiz Ant.o deSouza". Trata-se de um Códice muito curioso, em bom estado, apesar de não estar encadernado, nem as suas 54 fôlhas estão numeradas e rubricadas. Período de 1765 .

Vol. 29. - Livro de Registro de Ordens Reais e Leis da Câmara da Vila de Parnaíba. Periodo de 1769-1810. Trata-se de um Códice em bom estado; encadernado em pano; instrumentado com 140 fôlhas com a rubrica Per.a deS.a.

Vol. 30. - Livro dos Autos de Arrematações das Rendas. Periodo de 1770-1820. Trata-se de um Códice em bom estado, encadernado em pano. Instrumentado por 196 fôlhas com a rubrica Per.a deS.a.

Vol. 31. - Livro de Escrituras e Procurações do Tabelião de Parnaíba. Periodo de 1777-1812. Trata-se de um Códice em péssimo estado, necessitando de urgente restauração, capaz de sustar a total desintegração. As fôlhas sôltas trazem a rubrica Fam.

Vol. 32. - Livro de Escrituras do Tabelião da Vila de Santana de Parnaíba. Período de 1780-1783. Trata-se, como o anterior, de um Códice em péssimo estado, ainda mais estragado, pois lhe falta o comêço; não tem capa, fôlhas truncadas e, pelo têrmo de encerramento, teria 58 fólhas rubricadas com a palavra Roiz.

Vol. 33. - Livro de Vereanças da Câmara da Vila de Parnaíba. Período de 1785-1793. Trata-se de um Códice em es- 
tado regular; encadernado em pano; instrumentado por 100 fôlhas com a rubrica Barroco.

vol. 34. - Livro de Eleições. Período de 1787-1828. Trata-se de Códice em bom estado, encadernação de pano. Instrumentado com 100 fôlhas rubricadas Velozo e Gama.

Vol. 35. - Livro de Sumários do Juízo da Vila de Parnaíba. Período de 1789-1824. Códice em péssimo estado, necessitando de restauração. Inicialmente suas 52 fôlhas foram rubricadas com Fam. E posteriormente, novamente rubricadas, por razões que ignoramos, por Caetano Luiz de Barros Monteiro.

Vol. 36. - Livro de Vereanças da Câmara da Vila de Parnaíba. Período de 1793-1800. Trata-se de um Códice em bom estado; encadernado em pano. Instrumentado por 94 fôlhas com a rubrica Barros.

Vol. 37. - Livro de Escrituras e Procurações do Tabelião de Parnaiba. Período de 1793-1797. Trata-se de um Códice em péssimo estado, clamando por urgente restauração. FôIhas com a rubrica Miranda. Sem continuidade e incompleto.

Século XIX.

Vol. 38. - Livro de Vereanças da Câmara da Vila de Parnaíba. Periodo de 1800-1809. Trata-se de um Códice em bom estado, encadernado em pano. Fôlhas rubricadas com Almeida. Como singularidade: 2 fôlhas em branco; 98 fôlhas com texto e as 2 últimas em branco.

Vol. 39. - Livro da Fábrica, Jóias, Alfaias, Paramentos, etc., da Capela do Senhor Bom Jesus de Pirapora, "villa de Parnayba". Período de 1806-1838. Trata-se de Códice em bom estado; fôlhas rubricadas com "Procópio". 50 fôlhas com texto de 2 a 7 e de $46-v$. a 50 .

Vol. 40. - Livro de Vereanças da Câmara da Vila de Parnaíba. Período de 1809-1819. Trata-se de Códice em bom estado, encadernado em pano. Fôlhas com a rubrica "Miranda", apresentando a seguinte particularidade: 1 fôlha em branco, 196 fôlhas com o texto, última fôlha em branco.

Vol. 41. - Livro de Receita e Despêsa da Câmara da Vila de Parnaíba. Periodo de 1804-1829. Trata-se de um Códice em bom estado, encadernado em pano. Instrumenta-o 274 fôlhas com a rubrica Procópio, sendo que "o.texto vai até a fôlha $82-v$.

Vol. 42. - Livro de Registro da Câmara da Vila de Parnaíba. Periodo de 1810-1828. Trata-se de Códice em bom estado, encadernado em pano: Aprésenta 104 fôlhas com a rubrica Carv.o.

Vol. 43. - Livro de Notas do Tabelião de Parnaíba. Período de 1810-1880. Trata-se de Códice em bom estado. Apresenta 48 fôlhas com a rubrica Menezes. 
Vol. 44. - Livro de Notas do Tabelião de Parnaíba. Período de 1813-1820. Trata-se de Códice em bom estado. 99 fôlhas com a rubrica Olivra.

Vol. 45. - Livro do Juizo Ordinário de Parnaíba. Período de 18131837. Trata-se de Códice em bom estado. Apresenta 100 fôlhas com a rubrica Azevedo, sendo que o texto vai até fôlhas $84-v$.

Vol. 46. - Livro para Registro de Leis e Ordens Reais da Câmara da Vila de Parnaíba. Periodo de 1813-1828. Trata-se de Códice em bom estado, encadernado em pano. Instrumenta-o 102 fôlhas com a rubrica Azd.o, sendo que o texto vai até fôlhas $65-\mathrm{v}$.

Vol. 47. - Livro de Receita e de Despêsa da Câmara da Vila de Parnaíba. Período de 1816-1854. Trata-se de Códice em bom estado; encadernado em pano. Instrumenta- $\odot$ 150 fôlhas com rubrica Cruz e Chichorro.

Vol. 48. - Livro de Mandatos das Despesas da Câmara da Vila de Parnaíba. Período de 1816-1857. Códice em estado regular, encadernado em pano. Instrumenta-o 100 fôlhas com a rubrica Cruz, e posteriormente Chichorro.

Vol. 49. - Livro de Arrematações de Obras Públicas. Período de 1813-1888. Códice em estado regular, encadernado em pano, apresentando 50 fôlhas com a rubrica Arruda Veiga.

Vol. 50. - Livro de Registro da Câmara da Vila de Parnaíba. Período de 1819-1829. Códice em bom estado. Encadernado em pano. Integra-o 148 fôlhas com a rubrica Souto.

Vol. 51. - Livro de Vereadores da Câmara da Vila de Parnaíba. Período de 1820-1826. Códice em bom estado, encadernado em pano; integra-o 150 fôlhas com a rubrica Souto.

Vol. 52. - Livro de Arrematações da Câmara. Período de 18201835. Códice em bom estado; encadernado em pano. 100 fôlhas com as rubricas Carv.o e Chichorro.

Vol. 53. - Livro de Subscrição Voluntária para a Defesa do Império, da Câmara da Vila de Parnaíba. Ano de 1823 . Códice em bom estado, apresentando 18 fôlhas com a rubrica Penteado, sendo que o texto vai até fôlhas $12-v$.

Vol. 54. - Livro de Sumário de Querelas do Juízo da Vila de Parnaiba. Período de 1825-1830. Códice em estado precário, necessitando de restauração. Tem 25 fôlhas com a rubrica Chichorro.

Vol. 55. - Livro de Têrmos da Câmara da Vila de Parnaíba. Período de 1827-1829. Códice em estado regular, apresentando encadernação em pano. 100 fôlhas com a rubrica Barros.

Vol. 56. - Livro de Inventários dos Utensílios, livros e demais papéis da Câmara. Período de 1828-1829. Códice em estado regular. 31 fôlhas com a rubrica Chichorro. Como particularidadẹ: texto até a fôlha 6 . 
Vol. 57. - Livro de Eleições. Periodo de 1828-1833. Códice em bom estado, com encadernação em pano. Apresenta 100 fôlhas com a rubrica Cunha e Chichorro. Como particularidade, com texto até fôlha 18 .

Vol. 58. - Livro de Sessões da Câmara da Vila de Parnaíba. Período de 1829-1834. Códice em bom estado, com encadernação em couro. Apresenta 199 fôlhas com a rubrica AJliveira.

Vol. 59. - Livro de Posturas da Câmara da vila de Parnaíba. Periodo de 1829-1871. Códice em bom estado. 100 fôlhas com a rubrica Olivr.a. Como particularidade: com texto até fôlha 14 .

Vol. 60. - Livro de Registro da Câmara da Vila de Parnaíba. Periodo de 1829-1895. Códice em bom estado, encadernado em couro. Apresenta 193 fôlhas, com a rubrica Olivr.a.

Vol. 61. - Livro de lançamentos de operações, quitações e multas dos fiscais da Vila de Parnaíba. Período de 1830-1875. Códice em estado regular, encadernado em pano. Apresenta 127 fôlhas com a rubrica Olivr.a.

Vol. 62. - Livro das Despesas das Festas de Nossa Senhora do Carmo. Periodo de 1832-1846. Códice em estado regular. 100 fôlhas.

Vol. 63. - Livro de Lista Geral dos Jurados da Vila de Parnaíba e da Freguesia de Araçariguama. Periodo de 1833-1841. Códice em bom estado, encadernado em pano. Apresenta 50 fôlhas com a rubrica Morais, com a particularidade do texto ir até a fôlha 7 .

Vc1. 64. - Livro de lançamento das marcas e côr das rezes com nome das pessoas que matarem. Período de 1833-1890. Códice em estado regular. Apresenta 50 fôlhas com a rubrica Morais. Como particularidade: o texto vai até fôlhas 27.

Vol. 65. - Livro de Sessões da Câmara da Vila de Parnaíba. Período de 1834-1839. Códice em crtado regular. Apresenta 150 fôlhas com a rubrica Morais.

Vol. 66. - Livro de Alistamento da Guarda Policial. Ano: 1835. Códice em bom estado. Apresenta 40 fôlhas com a rubrica Morais.

Vol. 67. - Livro de Arrematações e Avenças do Município. Período de 1835-1844. Códice em bom estado, com encadernação em pano. Apresenta 50 fôlhas com a rubrica Morais.

Vol. 68. - Livro de Notas do Tabelião de Parnaíba. Periodo de 1836-1839. Códice em bom estado. Apresenta 48 fôlhas com a ribrica Villares:

Vol. 69. - Livro de Registro de Legados para as festas da Igreja e despesas das mesmas. Período de 1837-1846. Códice em bom estado, com encadernação em couro marron; apresentando 291 fôlhas. 
Vol: 70. - Livro de Sessões da Câmara da Vila de Parnaíba. Período de 1840-1846. Códice em bom estado; apresentando 140 fôlhas com a rubrica Cunha.

Vol. 71. - Livro das Eleições Primárias para a Paróquia da Vila de Santana de Parnaíba. Período de 1842-1844. Códice em bom estado; apresentando 154 fôlhas com a rubrica Cunha, com a particularidade de texto ir até fôlhas $7-v$.

Vol. 72. - Livro de Protocolo das Audiências do Juízo de Parnaíba. Periodo de $1842-\ldots$... Códice truncado, faltando Iôlhas, das quais restam apenas 7 , mesmo assim danificadas.

Vol. 73. - Livro das Notas do Tabelião de Parnaíba. Período de 1843-1851. Códice em bom estado. Apresenta 104 fôlhas com a rubrica Cunha. Como partscularidade o texto vai até fôlhas 73 .

Vol. 74. - Livro de Sessões da Câmara da Vila de Parnaíba. Periodo de 1846-1857. Códice em bom estado. Apresenta a seguinte e curiosa particularidade quanto à numeração: duas numerações. A mais antiga, de fôlhas 1 a $188 \mathrm{com}$ a rubrica S.a (Silva). Outra posterior, das fôlhas 1 a 192, com a rubrica AJliveira.

Vol. 75. - Livro de Receita e Despesas da Fábrica da Igreja Matriz da Senhora Santana da Vila de Parnaíba. Período de 1847-1859. Códice em estado regular. Apresenta 95 fôlhas com a rubrica Silva.

Vol. 76. - Livro de Atas da Revisão de Recursos. Período de 1847-1875. Códice em estado regular. 98 fôlhas com a rubrica Silva, como particularidade do texto ir até fôlhas 71 .

Vol. 77. - Livro de Atas das Juntas de Qualificações. Período de 1847-1862. Códice em bom estado. 37 fôlhas com a rubrica Silva.

Vol. 78. - Livro de lançamento do novo impôsto sôbre Tabernas e Botequins. Período de 1848-1865. Códice em estado regular. Instrumenta 93 fôlhas com a rubrica Silva, sendo que com texto até fôlhas 11 .

Yol. 79. - Livro de Atas das Eleições. Período de 1848-1872. Códice em bom estado. Instrumenta 96 fôlhas com 'a rubrica Silva, sendo que, com texto vai até fôlhas 31 .

vol. 80. - Livro de Atas de Eleições. Período de 1852-1872. Códice em bom estado. Apresenta 146 fôlhas com a rubrica F.co, sendo que com texto vai até fôlhas 38 .

Vol. 81. - Livro de Receita e Despêsa da Câmara da Vila de Parnaíba. Periodo de 1854-1883. Códice em bom. estado. Apresenta 145 fôlhas com a rubrica Serra.

Vol. 82. - Livro de Têrmos de Juramento dos Professôres Pú-f blicos de Primeiras Letras da Vila de Parnaiba. Pe- 
riodo de 1857-1866. Códice em bom estado. Apresenta 38 fôlhas com a rubrica S.Anna, sendo que com texto vai até fôlhas 4 :

Vol. 83. - Livro de Arrematações e Avenças do Município. Ano dè 1856. Códice em bom estado. Apresenta. 95 fôlhas com a rubrica Serra.

Vol. 84. - Livro de Sessões da Câmara da Vila de Parnaíba. Período de 1857-1867. Códice em bom estado. Apresenta 150 fôlhas com a rubrica Fonseca.

Vol. 85. - Livro de Impostos sôbre Carne Verde e de Águas Ardentes. Periodo de 1858-1865: Códice em bom estado. Apresenta 100 fôlhas com a rubrica Fonseca, sendo que o texto vai até fôlhas $10-v$.

Vol. 86. - Livro de Matrículas dos Guardas Nacionais. Período de 1859-1872. Códice em bom estado. Com a rubrica Barros, apresenta 201 fôlhas.

Vol. 87. - Livro de Atas das Juntas de Qualificações. Período de 1863-1875. Códice em bom estado. Apresenta 151 fôlhas com a rubrica Fam, sendo que com texto até fôlhas $100-v$.

Vol. 88. - Livro de Impostos sôbre portas e janelas. Período de 1865-1868. Códice em bom estado. Apresenta 50 fôlhas com a rubrica Moraes, sendo que com texto até fôlhas 31 .

Vol. 89. - Livro de Impostos sôbre Carne Verde. Período de 18651877. Códice em bom estado. Apresenta 50 fôlhas com a rubrica Moraes.

Vol. 90:- Livro de Impostos sôbre Águas Ardentes. Período de 1865-1878. Códice em bom estado. Apresenta 50 fôlhas com a rubrica Moraes.

Vol. 91. - Livro de Sepultamentos do Cemitério de Parnaíba. Período de 1868-1870. Códice em bom estado. Contém 178 fôlhas com a particularidade de não serem rubricadas.

vol. 92. - Livro de Atas das Eleições. Período de 1869-1880. Códice em bom estado. Apresenta 50 fôlhas com a particularidade de apresentar texto até fôlhas $15-\mathrm{v}$.

Vol...93. - Livro de Sepultamentos do Cemitério de Parnaíba. Período de 1870-1876. Códice em bom estado. Cumpre notar que além das fôlhas não numeradas, não traz têrmos de abertura e de encerramento.

Vol. 94. - Livro de Matrículas dos Guardas Nacionais. Ano de 1874. Códice em bom estado. Apresenta 99 fôlhas com a rubrica Ozorio Jr.

Vól.' 95. - Livro de Atas da Junta de Alistamento Eleitoral. Período de 1875-1892. Códice em bom estado, encadernado em pano. Apresenta 200 fôlhas com a rubrica Fam., sendo com texto até fôlhas 124 .

Vol: 96. - Livro de Alistamento dos Eleitores do Município Período de 1876-1880. Códice em bom estado. Apresenta 99 fôlhas com a rubrica Cruz, sendo que com texto até fôlhas 89 . 
Vol. 97. - Livro de Votantes da Junta Municipal de Parnaíba. Período de 1876-1880. Códice em bom estado. Apresenta 100 fôlhas com a rubrica Cruz, sendo que com texto até fôlhas 43 .

Vol. 98. - Livro de Atas das Eleições. Periodo de 1876-1880. Códice em bom estado. Apresenta 100 fôlhas com a rubrica Cruz, sendo que com texto até fôlhas 22 .

Vol. 99. - Livro de Atas das Eleições. Período de 1876-1878. Códice em bom estado. Apresenta 50 fôlhas com a rubrica Cruz, sendo que com texto até fôlhas 15-v.

Vol. 100. - Livro para classificação dos escravos que foram libertados pelo Fundo de Emancipação. Periodo de 18781886. Códice em bom estado. Apresenta 100 fôlhas com a rubrica Marques, sendo que com texto até fôlhas $9-\mathrm{v}$.

Vol. 101. - Livro de Impostos sôbre Águas Ardentes. Período de 1878-1893. Códice em bom estado. Apresenta 101 fôlhas com a rubrica Sant'Anna.

Vol. 102. - Livro de Sepultamentos do Cemitério de Parnaíba. Período de 1878-1893. Códice em bom estado. Apresenta 100 fôlhas com a rubrica Sant'Anna.

Vol. 103. - Livro de Atas da Instalação da Mesa Eleitoral. Período de 1881-1887. Códice em bom estado. Apresenta 200 fôlhas com a rubrica Fam.

Vol. 104. - Livro de Atas da Instalação da Mesa Eleitoral. Período de 1881-1926. Códice em bom estado. Apresenta 199 fôIhas com a rubrica Fam.

Vol. 105. - Livro de Atas de Eleições. Período de 1882-1886. Códice em bom estado. Apresenta 198 fôlhas rubricadas por Fam.

Vol. 106. - Livro de Subscriçã̀o Voluntária para a Defesa do Império, da Câmara da Vila de Parnaíba. Ano de 1823. Códice em bom estado. Apresenta 18 fôlhas com a rubrica Penteado, sendo que com texto até fôlhas 12-v.

Vol. 107. - Livro de Lançamento de Impostos de Capitação para as obras da Igreja Matriz. Periodo de 1887-1889. Códice em bom estado. Apresenta 300 fôlhas com a rubrica Fam.

Vol. 108. - Livro de Têrmos de infração de posturas municipais da Câmara da Vila de Parnaiba. Período de 1887-1900. Códice em bom estado. Apresenta 50 fôlhas com a rubrica Fam.

Vol. 109: - Livro de Têrmos de Contrato da Câmara de Parnaíba. Periodo de 1889-1904. Códice em bom estado. Como particularidade falta a primeira fôlha, sendo as 49 seguintes com a rubrica Branco.

Vol. 110. - Livro de Recibos de Título de Eleitor, de Parnaiba. Período de 1890-1693. Códice em bom estado, se bem que as fôlhas não estejam numeradas e nem rubricadas.

Vol. 111. - Livro de Atas da Câmara de Parnaiba. Periodo de 1890- 
1897. Códice em bom estado. Apresenta 200 fôlhas com a rubrica Olivr.a Castro.

Vol. 112. - Livro de Atas de Eleições. Período de 1890-1903. Códice em bom estado. Apresenta 200 fôlhas com a rubrica Cruz, sendo que com texto até fôlhas $62-\mathrm{v}$.

Vol. 113. - Livro de Alistamento de Eleitores. Período de 18921898. Códice em bom estado, todavia apresenta fôlhas sem numeração e sem rubrica.

Vol. 114. - Livro de Atas de Alistamento Eleitoral: Periodo de 1892-1903. Códice em bom estado. Apresenta 101 fôlhas com a rubrica Siq.ra, sendo que com texto até fôlhas 147 .

Vol. 115. - Livro de lançamento de Impôsto Predial. Período de 1892-1893. Códice em bom estado. Apresenta 101 fôlhas com a rubrica "Mauro". Como curiosidade cumpre mencionar que, sôlto no livro, há um caderno, ou melhor, um bloco de fôlhas almaço, intitulado: Lançamento de Impôsto Predial no Distrito de Pirapora, ano de 1905 .

Vol. 116. - Livro de Têrmos de Compromisso dos funcionários da Câmara de Parnaíba. Período de 1892-1911. Códice em bom estado. Apresenta 200 fôlhas com a rubrica Carvalho, sendo que com texto até fôlhas 42 .

Vol. 117. - Livro de Despesas da Câmara da Vila de Parnaíba. Periodo de 1895-1902. Códice em bom estado. Apresenta 200 fôlhas com a rubrica Cruz.

Vol. 118. - Livro para assinaturas dos Eleitores da 1a. Secção da Vila de Parnaíba. Período de 1897-1904. Códice em bom estado. Apresenta 48 fôlhas com a rubrica Paiva.

Século $\mathbf{X X}$.

Vol. 119. - Livro de Balancetes da Receita e Despêsa da Câmara de Parnaíba. Periodo de 1901-1904. Códice em bom estado. Apresenta 50 fôlhas com a rubrica ABranco.

Vol. 120. - Livro de Expediente da Intendência Municipal de Parnaíba. Período de 1902-1903. Códice em bom estado. Apresenta 50 fôlhas.

Vol. 121. - Livro de Despesas da Câmara de Parnaiba. Periodo de 1902-1904. Códice em bom estado. As 100 fôlhas não estão rubricadas.

Vol, 122. - Livro de lançamentos de Impostos Municipais. Ano de 1903. Códice em bom estado. Apresenta 100 fôlhas, com a rubrica B. Carvalho.

Vol. 123. - Livro de Receita e Despêsa da Câmara de Parnaíba. Período de 1904-1907. Códice em bom estado. Apresenta 50 fôlhas com a rubrica ABranco.

Vol. 124. - Livro de Sepultamentos do Cemitério de Parnaiba. Periodo de 1909-1912. Códice em bom estado. Todavia as 50 fôlhas não estão rubricadas. 
V́ol. 125. - Livro de Receita e Despêsa da Câmara de Parnaíba. Periodo de 1911-1918. Cónice em bom estado. Apresenta 200 fôlhas com a rubrica Procópio.

Vol. 126. - Livro de Ata da inauguração da rêde de esgôto da cidade de Parnaíba. Ano de 1912. Códice em bom estado. Apresenta 50 fôlhas numeradas e, com texto, até fôlhas $2-v$.

Vol. 127. - Copiador de ofícios expedidos pela Prefeitura Municipal. Periodo de 1914-1923. Códice em bom estado. Apresenta 50 fôlhas rubricadas por C. Rocha.

Vol. 128. - Livro de Matrículas dos Guardas Nacionais. Ano de 1916. Códice em bom estado. Apresenta 100 fôlhas com a rubrica Luz, sendo que com o texto até fôlhas 7 .

Vol. 129. - Livro de Mandados ou Ordens de Pagamento. Período de 1917-1920. Códice em bom estado. Apresenta 200 fôlhas com a rubrica Procópio.

Vcl. 130. - Livro de Sepultamentos do Cemitério de Parnaíba. Período de 1917-1921. Códice em bom estado. Apresenta 50 fôlhas com a rubrica Procópio.

Vol. 131. - Livro de Sepultamentos do Cemitério de Parnaíba. Período de 1921-1926. Códice em bom estado. Apresenta 50 fôlhas com a rubrica Oliveira.

Vol. 132. - Copiador de ofícios expedidos pela Prefeitura Municipal. Ano de 1925. Códice em bom estado. Apresenta 50 fôlhas, sendo que com texto até fôlhas 16 .

Vol. 133. - Livro para assinaturas dos Eleitores da 1a. Secção do Município. Período de 1926-1927. Códice em bom estado. Apresenta 50 fôlhas com a rubrica Procópio, sendo que com o texto até fôlhas $9-v$.

Vol. 134. - Livro de Iançamento de Impôșto Predial. Ano de 1932. Códice em bom estado. Apresenta 30 fôlhas com a rubrica Cap. A. Pacheco.

\section{MARIA REGINA DA CUNHA RODRIGUES} Professôra da Cadeira de História da Civilização Brasileira da Faculdade de Filosofia, Ciências e Letras de Santos: 